Vol. 6(9), pp. 119-127, September 2014

DOI: 10.5897/J PBC S2014.0449

Artic le Number: $7196 F 2846884$

ISSN 2006-9758

Copyright $\odot 2014$

Journal of Plant Breeding and Crop

Author(s) retain the copyright of this artic le

http://www.academic joumals.org/IPBCS

\title{
Effects of yield components on yield potential of some lowland rice (Oyza sativa L.) in coastal region of Southern Nigeria
}

\author{
Andrew A. Efisue*, Bianca C. Umunna and Joseph A. Orluchukwu \\ Development of Crop and Soil Science, University of Port Harcourt, P. M. B. 5323 Port Harcourt, Rivers State, Nigeria.
}

Received 28 February, 2014; Accepted 26 June, 2014

\begin{abstract}
The coastal region of Nigeria has abundant water naturally good for rice production, which is untapped due to oil exploration. The study was conducted to access the relationship between grain yield (GY) and its components of twenty-six segregating lines for the coastal region of Southern Nigeria. The experiment was conducted at the University of Port Harcourt teaching and Research Institution of Faculty of Agriculture and replicated three times in a complete block design. Data was collected on yield components such as number of tillers per plant, leaf area index (LAI), total GY at maturity, and grain weight per panicle at maturity. About 8 lines had more tiller number than the general mean value (30) at maximum tillering stage of the rice crop, while lines with high effective tiller numbers were IRBW-180 (49) and IRBW-147 (48). GY significantly positively correlated with effective tiller number, grain weight per plant, number of grain per panicle and grain weight per panicle. The cluster analysis for genetic diversity revealed three major groupings (A, B and C). The genotypes in Group A posses the character of high grain weight and Group B posses characters for long panicle and high value of flag LAI (FLAI), which indicates broad leaf for light interception thus enhancing photosynthesis. In Group C, genotypes posses varying characters, however, high value of LAI and tall plant, which indicates tendency of good nutrient utilization. Soil in this region is saline and effect crop performance especially rice, these identified indexes will facility the breeding for this region.
\end{abstract}

Key words: Oryza sativa L., yield components, yield potential, segregating lines, cluster.

\section{INTRODUCTION}

Rice is an important annual crop in Nigeria. It is one of the major staples. The crop is commonly consumed even as a food crop for household food security. The average Nigerian consumes $24.8 \mathrm{~kg}$ of rice per year, representing $9 \%$ of annual calorie intake (IRRI, 2001). Thus, rice has, become a strategic commodity in the Nigerian economy.
The three main production ecologies for rice in Nigeria are lowland rice, upland rice and irrigated rice. Among these, lowland rice has the highest priority being the ecology that represents the largest share of rice area and rice production.

Grain yield (GY) in cereals is one of the most important 
and complex traits in plant breeding experiments. Continue improvement of GY remains the top priority in most of the breeding programmes (Yan et al., 2002). In rice, GY depends on various growth and yield component traits such as the panicle number per plant, the filled grain number per panicle, and the weight per grain (Yoshida, 1983). Breeders have paid much attention to the concept of plant ideotypes and proposed several models for highyielding rice, such as the 'heavy-panicle' and the 'multipanicle' types. Thus, an increase in GY could be effectively achieved through yield component improvement since yield components have higher heritability than GY (Xiong, 1992). The agronomic value of a variety depends on many characteristics (Huang et al., 1991) and the most important characteristics are high yielding ability, resistance to diseases and pests, resistance to undesirable environmental factors and high quality of the products. But, the final aim is to increase the GY of rice (Swaminathan, 1999).

Rice GY is determined by several agronomic characters such as heading days, days to maturity, grain filling period, number of productive tiller, number of fertile grain per panicle, panicle length, 1000 grain weight and plant height (Halil and Necmi, 2005). Yield is a quantitative trait, greatly influenced by environmental fluctuations. Study on yield contributing characters assumes greater importance of fixing up characters that influence yield (Prasad et al., 2001; Kole and Hasib, 2008). A statistical analysis has been used to measure the mutual relationships between various characters and yield improvement. Genotypic evaluation of yield components could assist to identify their relationships with GY.

Tillering plays an important role in determining rice GY since it is closely related to panicle number per unit ground area. Too few tillers result in too few panicles, but excess tillers caused higher tiller mortality, small panicles, poor grain filling and consequent reduction in GY (Peng et al., 1994). In rice, the manipulation of tiller number is important for GY, but the physiological basis of the regulation of tiller growth remains unclear. In general, large tillers result in higher sink: source ratio, spikelet number, proportion of filled grains, leaf area (LA) per tiller and sink capacity (Choi and Kwon, 1985).

Leaf area index (LAI) is LA per unit ground area and is an important crop biophysical parameter. High leaf index was reported by Efisue et.al. (2009) which indicated that LAI is a good selection criteria for increasing GY of rice. Thus, varieties with higher value of LAI could yield better than varieties with low LAI. Plant height is the predominant factor determining the nitrogen response of rice plant. It determines the lodging behaviour thus deciding yield. Lodging disturbs leave display resulting in shading thus increasing the percentage of unfilled grain. High heritability coupled with high genetic advancement for these traits provide enough confidence for selection of desirable genotypes (Ali et al., 2002).

The number panicle with filled grains determines the ultimate yield of the crop. Thus, effective panicles should have high ripening percentage and high grain to straw ratio (harvest index). Panicles affect yield capacity, as yield capacity is determined by the number of grain per unit area and potential size of grains (Feil, 1992). Cultivars with larger grain size tend to have higher grain filling rate, resulting in higher assimilate accumulation and heavier grain weight (Jones et al., 1979; Jeng et al., 2003). Thus, the above information leads into this study in the coastal region of Nigeria.

The coastal region of Nigeria has abundant water naturally good for rice production, which is untapped due to oil exploration. Rice breeding for this region is timely and could curb youth restiveness. This could be done by examine yield components that will enhance rice production in the region. The study of this experiment is to examine the effects of some yield components of some lowland rice on yield that will enhance rice production.

\section{MATERIALS AND METHODS}

The experimental plot was located at the University of Port Harcourt, Faculty of Agriculture Teaching and Research Farm. Geographically, Rivers State is located in southern part of Niger Delta, Nigeria. It has an average temperature of 28 to $30^{\circ} \mathrm{C}$ and rainfall ranging from 2000 to $2680 \mathrm{~mm}$ per annum. Twenty-six segregating lines at $F_{3}$ generations were used for the experiment as indicated in Table 1.

\section{Design and planting}

It was a potted experiment in randomized complete block design in three replications. Four seeds were sown per pot and thinned to two seedlings after 15 days of emergence. Planting was done by seed dibbling at seeding rate of $60 \mathrm{~kg} / \mathrm{ha}$. Irrigation was applied as at when due to maintain soil capacity. Inorganic fertilizer (NPK 15:15:15 ) was applied in a basal application of $200 \mathrm{~kg} \mathrm{ha}^{-1}\left(\mathrm{~N}_{2}\right.$, $\mathrm{P}_{2} \mathrm{O}_{5}$ and $\left.\mathrm{K}_{2} \mathrm{O}\right)$ and top dressed with $65 \mathrm{~kg} \mathrm{ha}^{-1}$ urea at tillering and $35 \mathrm{~kg} \mathrm{ha}^{-1}$ at booting.

\section{Data collection}

Data was collected at appropriate stage of the crop development. The agronomic characters were measured at weekly intervals. The 'Standard Evaluation System (SES) for Rice' reference manual (IRRI, 1996) was used for all trait measurements except where stated otherwise. The following data was collected at the appropriate crop phenology: Data was taken from five (5) plants of each line. Plant height was measured in $\mathrm{cm}$ from the plant base to the tip of the highest leaf. Effective tillers of each plant were counted to determine the total number of panicles in each plant. Panicle length of the central tiller of the each plant was measured using a meter rule. Two young fully expanded leaves from the main stem were randomly selected in each pot and LA was determined using a LA meter (li-3100, Lincoln, NE USA). LAI was calculated as described by Yoshida (1981) as follows:

$\mathrm{LAI}=$ (sum of the LA of all leaves / unit area where the leaves have been collected).

The number of filled grains (seeds) per panicle taken from the main tiller of each plant was counted at maturity stage separately after harvesting. Grain weight per panicle for each variety was measured 
Table 1. Genetic material used, source and their peculiar agronomic traits.

\begin{tabular}{lll}
\hline Genotype & Sources & Peculiar traits \\
\hline IRBW-125 & AGRA germplasm of Uniport & Tall plant \\
IRBW-54 & AGRA germplasm of Uniport & Tall plant \\
IRBW-26 & AGRA germplasm of Uniport & Short plant \\
IRBW-144 & AGRA germplasm of Uniport & Tall plant \\
IRBW-156 & AGRA germplasm of Uniport & Short plant \\
IRBW-399 & AGRA germplasm of Uniport & High tillering ability \\
IRBW-440 & AGRA germplasm of Uniport & Tall plant \\
IRBW-255 & AGRA germplasm of Uniport & Tall plant \\
IRBW-148 & AGRA germplasm of Uniport & Short panicle \\
IRBW-295 & AGRA germplasm of Uniport & Short plant \\
IRBW-275 & AGRA germplasm of Uniport & Long panicle \\
IRBW-279 & AGRA germplasm of Uniport & High tillering ability \\
IRBW-467 & AGRA germplasm of Uniport & Tall plant \\
IRBW-274 & AGRA germplasm of Uniport & Short plant \\
IRBW-263 & AGRA germplasm of Uniport & Tall plant \\
IRBW-246 & AGRA germplasm of Uniport & High tillering ability \\
IRBW-202 & AGRA germplasm of Uniport & High yield \\
IRBW-103 & AGRA germplasm of Uniport & Tall plant \\
IRBW-180 & AGRA germplasm of Uniport & Tall plant \\
IRBW-307 & AGRA germplasm of Uniport & High yield \\
IRBW-166 & AGRA germplasm of Uniport & High tillering ability \\
IRBW-252 & AGRA germplasm of Uniport & High grain weight \\
IRBW-123 & AGRA germplasm of Uniport & Long panicle \\
IRBW-147 & AGRA germplasm of Uniport & High yield \\
IRBW-105 & AGRA germplasm of Uniport & High grain weight \\
IRBW-427 & AGRA germplasm of Uniport & High yield \\
\hline & & \\
\hline
\end{tabular}

after harvesting. The plant yield was measured in grams after harvest for each variety.

\section{Data analysis}

All data were subjected to analysis of variance using GenStat discovery ( $4^{\text {th }}$ Edition) for mean separation, correlation analysis and means of the traits. Pair-wise distance matrixes between genotypes were again derived using the numerical taxonomy and multivariate analysis system (NTSYS-PC), Version 2.1 (Rohlf, 2000) and the Jaccard coefficient of similarity (Jaccard, 1908). Genetic diversity dendogram for the genotypes was created by Unweighted pair group method with arithmetic mean (UPGMA) cluster analysis (Sneath and Sokal, 1973; Swofford and Olsen, 1990).

\section{RESULTS}

About eight genotypes performed better than the overall mean of the LAI (Table 2). The genotype with the highest LAI was IRBW-125 followed by IRBW-54 and the least was IRBW-279. The LAl showed highly significance difference among the tested genotypes. The flag LAI (FLAI) indicates a significant difference among the rice genotypes. IRBW-54 had the highest value of FLAI (1.10) and the least was IRBW-399(0.18). The genotypes with the highest panicle length is IRBW-123(20.64) and the least IRBW-148(13.87) showing a highly significance difference among the rice genotypes tested (Table 2).

Eight genotypes performed better than the overall mean of plant height and genotypes with highest plant height are IRBW-54(101.00), IRBW 103(101.00) and IRBW125(101.00), while the least is IRBW-148(60.7). Plant height has significance difference among the genotypes tested. The result for the tiller number showed that about eight genotypes had more tiller number than the overall mean at maximum tillering stage of the rice crop (Table 3 ). The effective tillers which, is the number of tillers harvestable per plant, gave a mean value of 31.19 at maturity of the plant. The highest effective tiller rice genotypes are IRBW-180(49), IRBW-147(48), whilst the least is IRBW-440(7). Tilling ability of the genotypes also indicate a highly significance difference among the genotypes tested. About seven genotypes performed better than other genotypes for GY per plant with the highest been IRBW-180(224.42 g) and the least IRBW$54(34.00 \mathrm{~g})$. The results indicate a significance difference among the genotypes tested (Table 3).

The genotype with the highest grain weight per panicle was IRBW- 166 (4.17 g) followed by IRBW-105(4.01 g) 
Table 2. Agronomic performance of some lowland rice genotypes.

\begin{tabular}{lccc}
\hline Genotype & LAI & FLAI & Panicle length (cm) \\
\hline IRBW-125 & 3.38 & 0.94 & 20.54 \\
IRBW-54 & 3.30 & 1.10 & 19.71 \\
IRBW-26 & 2.89 & 0.95 & 20.15 \\
IRBW-255 & 2.49 & 0.68 & 20.36 \\
IRBW-467 & 2.43 & 1.00 & 20.17 \\
IRBW-105 & 2.24 & 0.72 & 20.56 \\
IRBW-252 & 2.23 & 0.78 & 20.36 \\
IRBW-123 & 2.18 & 0.62 & 20.64 \\
IRBW-147 & 2.14 & 0.57 & 20.45 \\
IRBW-295 & 2.08 & 0.55 & 19.56 \\
IRBW-180 & 2.07 & 0.40 & 20.63 \\
IRBW-144 & 2.05 & 0.61 & 19.11 \\
IRBW-202 & 1.93 & 0.92 & 19.82 \\
IRBW-103 & 1.92 & 0.48 & 19.55 \\
IRBW-427 & 1.74 & 0.61 & 20.42 \\
IRBW-166 & 1.72 & 0.63 & 19.71 \\
IRBW-263 & 1.70 & 0.45 & 17.65 \\
IRBW-275 & 1.51 & 0.56 & 19.72 \\
IRBW-399 & 1.49 & 0.18 & 19.47 \\
IRBW-246 & 1.47 & 0.40 & 20.15 \\
IRBW-274 & 1.41 & 0.39 & 20.45 \\
IRBW-156 & 1.357 & 0.44 & 19.17 \\
IRBW-307 & 1.28 & 0.53 & 18.42 \\
IRBW-440 & 1.26 & 0.30 & 16.79 \\
IRBW-148 & 1.21 & 0.38 & 13.87 \\
IRBW-279 & 1.12 & 0.57 & 24.24 \\
MEAN & 1.92 & 0.63 & 19.53 \\
LSD(0.05) & $0.686^{\star * *}$ & $0.326 * * *$ & $2.695^{\star * *}$ \\
CV(\%) & 21.80 & 31.80 & 8.40 \\
\hline LAI Leaf & & & \\
\hline
\end{tabular}

LAI $=$ Leaf area index, FLAI $=$ Flag leaf area index, ${ }^{* * *}$ significant at 0.001 probability level respectively

and the least IRBW-148(1.73 g). The grain weight showed highly significance difference among the genotypes tested. While genotype with the highest number of grain per panicle is IRBW-180 (131), followed by IRBW-166(122) and the least was IRBW-148(51) (Table 4).

FLAI significantly correlated with grain weight per panicle and number of grain per panicle at probability level of 0.05 . While significance correlation at probability level of 0.001 was observed for LAl with FLAI (Table 5). Effective tiller number indicates a significant correlation with yield per plant, maximum tillering and number of grain per panicle. Grain weight per panicle indicates a significant correlation among some traits tested such as yield per plant, number of grain per panicle, and LAI (Table 5). LAI indicates a significant correlation with number of grain per panicle. Number of grain per panicle showed a significant correlation with yield per plant and maximum tillering (Table 5). At maximum, tillering indicates significant correlation with yield per plant in (Table 5). Yield per plant are highly and significantly correlated with effective tiller number, grain weight per panicle, number of grain per panicle and at maximum tilling stage of the crop at 0.001 probability level of significance.

\section{Cluster analysis}

Hierarchical cluster analysis of some agronomic traits and yield are presented in the Figure 1. Three main groups $(A, B$, and $C$ ) were identified at $0.02 \%$ coefficient of similarity index. The dendrogram revealed each group containing 11, 7 and 8 genotypes for A, B and C, respectively. At $0.04 \%$ of coefficient of similarity index, eight groups were identified and further down the similarity 
Table 3. Agronomy performance of some lowland rice genotypes.

\begin{tabular}{lcccc}
\hline Genotype & $\begin{array}{c}\text { Yield per } \\
\text { plant (g) }\end{array}$ & $\begin{array}{c}\text { plant height at } \\
\text { maturity }(\mathbf{c m})\end{array}$ & $\begin{array}{c}\text { Number of tillers at } \\
\text { maximum tillering stage }\end{array}$ & $\begin{array}{c}\text { Number of effective } \\
\text { tillers at maturity }\end{array}$ \\
\hline IRBW-180 & 224.42 & 90.40 & 53 & 49 \\
IRBW-123 & 176.00 & 80.90 & 47 & 43 \\
IRBW-427 & 162.00 & 80.70 & 26 & 28 \\
IIRBW-252 & 147.00 & 90.40 & 50 & 45 \\
IRBW-147 & 140.00 & 90.70 & 52 & 48 \\
IRBW-166 & 129.00 & 80.90 & 33 & 31 \\
IRBW-105 & 124.00 & 90.40 & 37 & 31 \\
IRBW-274 & 91.30 & 100.00 & 26 & 28 \\
IRBW-399 & 84.00 & 70.20 & 30 & 34 \\
IRBW-467 & 77.50 & 90.70 & 24 & 24 \\
IRBW-279 & 72.30 & 80.40 & 29 & 33 \\
IRBW-125 & 68.50 & 101.00 & 22 & 21 \\
IRBW 307 & 68.10 & 60.90 & 35 & 30 \\
IRBW-275 & 66.20 & 70.60 & 23 & 26 \\
IRBW-263 & 61.60 & 100.00 & 22 & 26 \\
IRBW-144 & 60.00 & 100.00 & 29 & 25 \\
IRBW-202 & 60.00 & 90.40 & 24 & 20 \\
IRBW-103 & 56.70 & 101.00 & 27 & 27 \\
IRBW-156 & 54.60 & 70.00 & 19 & 20 \\
IRBW-440 & 54.00 & 90.90 & 25 & 7 \\
IRBW-148 & 53.60 & 60.70 & 33 & 31 \\
IRBW-26 & 51.20 & 70.60 & 18 & 17 \\
IRBW-295 & 51.30 & 100.00 & 21 & 18 \\
IRBW-255 & 46.80 & 100.00 & 16 & 20 \\
IRBW-246 & 41.60 & 90.50 & 21 & 20 \\
IRBW-54 & 34.00 & 101.00 & 17 & 20 \\
Mean & 86.70 & 86.67 & 31.2 & 3.246 \\
S.E & 2.530 & 2.281 & 3.439 & 47.65 \\
CV(\%) & 14.90 & 38.70 & 39.90 &
\end{tabular}

index at $0.11 \%$ majority of the genotypes assumed individual identity.

The genotypes in Group A posses the character of high grain weight and Group B posses characters for long panicle and high value of FLAl, which indicates broad leaf for light interception for enhancing photosynthetic activities in plant. In Group C, genotypes posses varying characters, however, high value of LAl and tall plant, which indicates tendency of good nutrient utilization (Table 5).

\section{DISCUSSION}

\section{Performance of some agronomic traits of lowland rice}

One of the main objectives of any breeding program is to produce high yielding and better quality lines for release as cultivars to farmers. Detailed information on rice yield component that contributes to high yield is needed from which desired lines are to be selected for further manipulation to achieve the target. Introduction of new populations can be made from one region to the other easily and may be used for further manipulation to develop breeding lines. Various yield components are directly or indirectly responsible for rice yield potentials.

Grain weight per panicle is a varietal trait and of secondary importance in determining rice yield. Grain weight is determined by the source capacity (photosynthetic leaves) to supply assimilate during the ripening period, and by sink capacity (developing grain) to accumulate the imported assimilate (Ntanos and Koutroubas, 2002). Cultivars with larger grain weight value size tend to have higher grain filling rate, resulting in higher assimilate accumulation and heavier grain weight. Thus, genotype IRBW-166(4.17) has the highest grain weight per panicle value among the varieties 
Table 4. Genotype performance based on number of grain and grain weight per panicle.

\begin{tabular}{|c|c|c|}
\hline Genotype & No. of grains per panicle & Grain weight per panicle (g) \\
\hline IRBW-54 & 62 & 2.11 \\
\hline IRBW-180 & 131 & 3.43 \\
\hline IRBW-467 & 94 & 3.23 \\
\hline IRBW-26 & 88 & 3.00 \\
\hline IRBW-125 & 95 & 3.26 \\
\hline IRBW-202 & 88 & 3.01 \\
\hline IRBW-252 & 95 & 3.25 \\
\hline IRBW-105 & 117 & 4.01 \\
\hline IRBW-255 & 68 & 2.34 \\
\hline IRBW-166 & 122 & 4.17 \\
\hline IRBW-123 & 119 & 3.67 \\
\hline IRBW-144 & 70 & 2.41 \\
\hline IRBW-427 & 101 & 3.45 \\
\hline IRBW-147 & 85 & 2.90 \\
\hline IRBW-279 & 64 & 2.20 \\
\hline IRBW-275 & 75 & 2.57 \\
\hline IRBW-295 & 83 & 2.85 \\
\hline IRBW-307 & 66 & 2.26 \\
\hline IRBW-103 & 61 & 2.08 \\
\hline IRBW-263 & 69 & 2.37 \\
\hline IRBW-156 & 80 & 2.73 \\
\hline IRBW-246 & 61 & 2.10 \\
\hline IRBW-274 & 95 & 3.26 \\
\hline IRBW-148 & 51 & 1.73 \\
\hline IRBW-440 & 60 & 2.05 \\
\hline IRBW-399 & 70 & 2.41 \\
\hline Mean & 84 & 2.80 \\
\hline LSD (0.05) & $35.9^{\star \star \star *}$ & $1.246^{\star \star}$ \\
\hline $\mathrm{CV}(\%)$ & 26.2 & 27.1 \\
\hline
\end{tabular}

**, ${ }^{* \star *}$ significant at 0.01 and 0.001 probability level, respectively.

Table 5. Correlation coefficient between rice yield and its yield components.

\begin{tabular}{|c|c|c|c|c|c|c|c|c|}
\hline \multicolumn{9}{|l|}{ EFF_till } \\
\hline FLAI & $0.1443^{\mathrm{ns}}$ & & & & & & & \\
\hline GWt_Pani & $0.3650^{\mathrm{ns}}$ & $0.4052^{*}$ & & & & & & \\
\hline LAI & $0.1762^{\mathrm{ns}}$ & $0.7977^{\star \star *}$ & $0.3995^{\star}$ & & & & & \\
\hline NG_Pani & $0.4741^{*}$ & $0.4571^{*}$ & 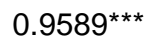 & $0.4828^{*}$ & & & & \\
\hline PANLT & $0.3597^{\mathrm{ns}}$ & $0.3124^{\mathrm{ns}}$ & $0.2494^{\mathrm{ns}}$ & $0.2504^{\mathrm{ns}}$ & $0.2279^{\text {ns }}$ & & & \\
\hline Plt_Ht & $0.2385^{\mathrm{ns}}$ & $0.0616^{\mathrm{ns}}$ & $0.0365^{\mathrm{ns}}$ & $0.1036^{\mathrm{ns}}$ & $0.0723^{\mathrm{ns}}$ & $-0.1722^{\mathrm{ns}}$ & & \\
\hline Tillmax & $0.9043^{\star \star *}$ & $0.0948^{\mathrm{ns}}$ & $0.3762^{\mathrm{ns}}$ & $0.1652^{\mathrm{ns}}$ & $0.493^{\star}$ & $0.0907^{\mathrm{ns}}$ & $0.2836^{\mathrm{ns}}$ & \\
\hline \multirow[t]{2}{*}{ Yld_Plt } & $0.7986^{\star \star \star}$ & $0.3543^{\mathrm{ns}}$ & $0.6900^{\star \star *}$ & $0.3208^{\mathrm{ns}}$ & $0.8070^{\star * *}$ & $0.1717^{\mathrm{ns}}$ & $0.2149^{\mathrm{ns}}$ & $0.8201^{* \star *}$ \\
\hline & Eff_till & FLAI & GWt_Pani & LAI & NG_Pani & PANLT & Plt_Ht & Tillmax \\
\hline
\end{tabular}

$*^{* *}$, and ${ }^{* *}$ significant at $0.05,0.01$ and 0.001 probability level respectively, ns $=$ non significant. EFF_TILL= EFfective tillers, FLAI = Flag leaf area index. GWT_Pani = Grain weight per panicle, LAl = leaf area index, NG_Panicle =Number of grain per panicle, PANLT $=$ Panicle length, $\mathrm{PLT} \_\mathrm{Ht}=$ Plant height, Tillmax $=$ Maximum tillering, $\mathrm{YLd} \_\overline{\mathrm{p}} \mathrm{Lt}=\mathrm{yYield}$ per plan .

observed and may possess higher grain filling rate followed by genotype IRBW-105(4.01) and the least genotype IRBW-148(1.73). These results corroborate earlier reports (Jones et al., 1979; Jeng et al., 2003). The 


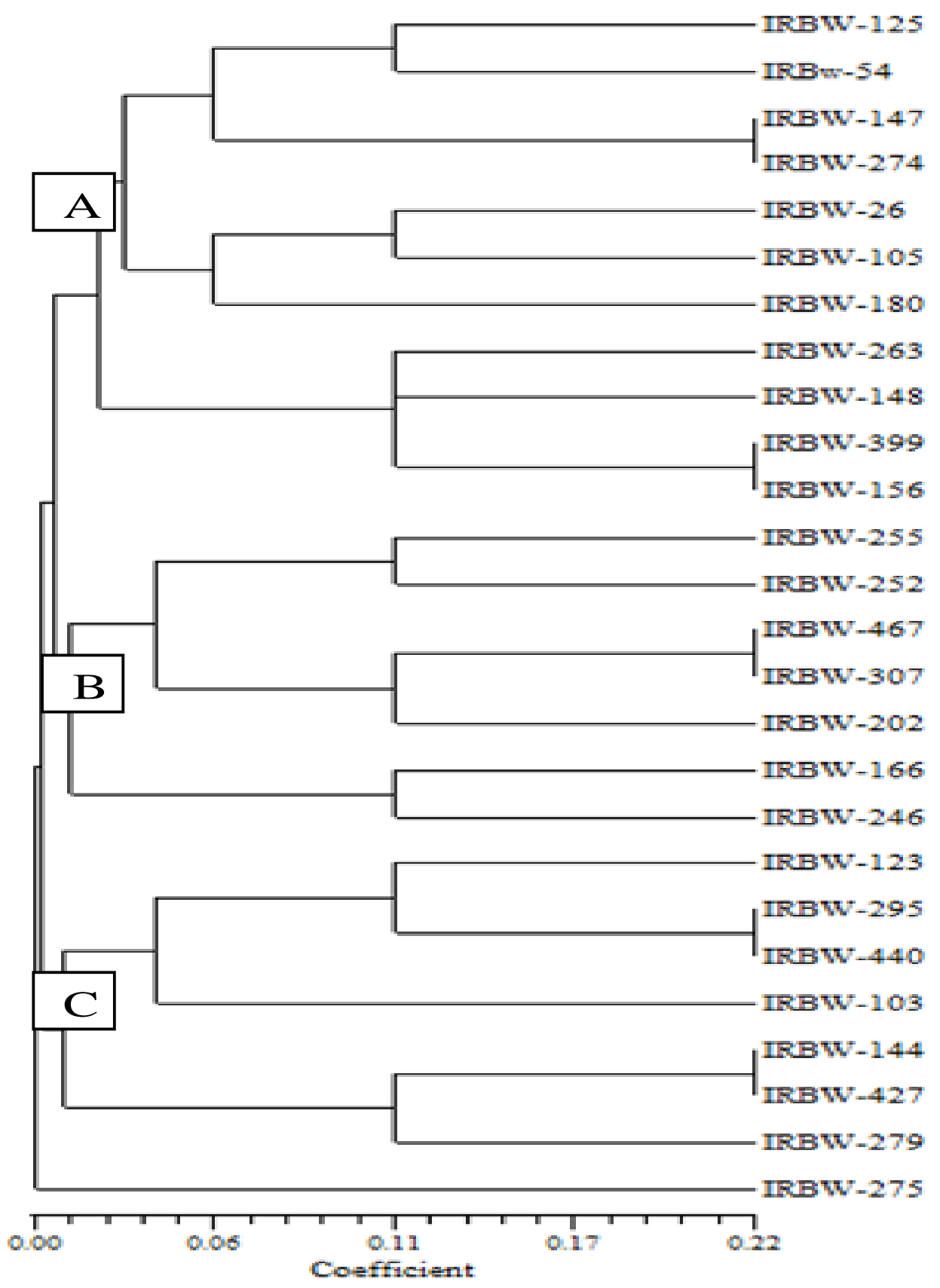

Figure 1. Dendogram showing genetic diversity of the entries.

number of grains per panicle is important yieldcontributing characters. Feil (1992) reported that among the components of GY of a cereal crop, the number of spikelets per panicle appeared to be a predominant key character in the development of high-yielding cultivars. Thus genotype IRBW-180(131) and IRBW-166(122) of higher number of grains per panicle could be of high yielding.

LAl is the efficiency of photosynthetic process, contributing greatly to yield. High leaf index was reported by Efisue et al. (2009) which indicated that LAl is a good selection criterion for increasing $G Y$ of rice. Thus, genotypes with higher value of LAl could be higher yielding compared to low LAI genotypes, example, IRBW125(3.383 of higher LAI and IRBW-279(1.103) lowest. FLAI played an important role in rice yield by increasing grain weight with high photosynthetic ability (Mohashami, 1998). Therefore, genotype IRBW-54 could be high yielding with FLAI (1.103).

The panicle determines the ultimate yield of the crop, as the length of a panicle determines the number of grain to be accommodated. This indicates that genotype with 
long panicles will accommodate more grains than short panicles genotype. Thus, genotypes with long panicle could possess high yielding ability such as IRBW-123 (20.64) compared to IRBW-148 (13.87). Plant height is the predominant factor determining the nitrogen response of rice plant. It determines the lodging behaviour thus deciding yield. On the other hand, tall stature facilitates light penetration (Chandrasekaran et al., 2007), which may increase photosynthetic activities of plant. Aside from these good agronomic traits, tall plants easily lodge; this behaviour has negative effects on yield production. This suggest that there should be a balance where breeders develop varieties with strong culm (stem) that will resist lodging and fertilizer responsive that may translate to high yield such as IRBW-54(100.6) and IRBW-295(100.3) genotypes.

Tillering ability in rice is an important agronomy trait for grain production. Ibrahim et al. (1990) found out that effective tillers were most reliable character in selecting genotypes of rice for higher yield. Tillering plays an important role in determining rice GY since it is closely related to panicle number per unit ground area. Too few tillers result in too few panicles, but excess tillers caused hight tiller mortality, small panicles, poor grain filling and consequent reduction in GY (Peng et al., 1994). Higher tillers results in higher sink: source ratio, spikelet number, proportion of filled grain, LA per panicle and sink capacity (Choi and Kwon, 1985). Therefore, genotypes with high productive tillering ability could exhibit the aforementioned characters such as IRBW-180(49) and IRBW-147(48).

Rice GY is determined by several agronomic characters such as heading days, days to maturity, grain filling period, number of fertile tiller, number of fertile grain per panicle, panicle length, and plant height (Halil and Necmi, 2005). The result from the experiment showed that IRBW$180(224.42 \mathrm{~g})$ has the highest GY per plant among the genotypes tested, followed by IRBW-123 (176.00 g). The above genotypes could be deployed to farmers' field to enhance food production.

\section{Relationship of some agronomic traits and yield}

Data analysis regarding yield per plant indicates a highly significant association with maximum tillering, effective tiller number, grain weight per plant and number of grain per panicle. These relations mean that any increase in any one aforementioned yield components causes increase in GY. However, yield components have different effects on GY, depending on the contributing genes to GY. The number of grain per panicle showed a significant correlation with yield per plant, maximum tillering. This high and significant correlation indicates that number of grain per panicle is largely responsible for the determining GY in individual plants. Similarly, Mirza et al. (1992) found that number of grains panicle is positively correlated with panicle length, 1000-grains weight and GY. A significant variation was observed for grain per panicle amongst the genotypes examined, indicating broad genetic base of the genetic materials used in the study.

Effective tiller number indicated a significant correlation with yield per plant, maximum tillering and number of grain per panicle as expressed by genotypes IRBW-180 and IRBW-123. The FLAI results showed a significant correlation with grain weight per panicle, LAI and number of grain per panicle. This report is in conformity with Bharali et al. (1994) who found higher direct effect of FLAI on grain. LAl indicated a significant correlation with number of grain per panicle, grain weight per panicle and FLAI. LAI is a secondary trait for the selection of high yield of most crops and positively highly correlation was observed for the aforementioned traits. Thus indicates that large LAl value will result to increase in yield as equally observed by Ghosh and Singh (1998). Grain weight per panicle results indicate a significant positive correlation among some traits tested such as yield per plant, number of grain per panicle.

\section{Conclusion}

Plant breeders should focus more on the aforementioned traits that showed high association with GY, especially effective tiller number, grain weight per panicle and number of grains per panicle. Rice yield components are found to improve GY as observed from this experiment. Significant and positive correlation between tiller numbers and yield observed in study indicates that varieties with high tillering ability could yield more in response to increase in tiller numbers. Effective tillers results in higher grain as observed in genotype IRBW-180 and IRBW-123, breeders should therefore pay keen interest for higher effective tiller numbers in rice crop.

LAI and FLAl played an important role in rice GY production, because of their relationships with photosynthesis for the production of assimilates for the plant. Therefore, selection for these traits in the development of rice varieties will increase GY. This will inevitably increases the livelihood of our rice farmers. Also, in the development of a rice variety, selection for large grain size and fast grain filling rate through breeding program may be a feasible approach to increase the GY in rice. Thus, these varieties are recommended that IRBW-123 possess panicle length and high yield per plant, while IRBW-180 had the highest yield per plant and IRBW-166 had the highest grain weight per panicle, these genotypes could be deployed into farmers' field to increase rice production in Nigeria.

\section{REFRENCES}

Ali Z, Khan AS, Asad MA (2002). Drought tolerance in wheat: Genetic variation and heritability for growth and iron relation. Asian J. Plant Sci. 1:420-422. 
Bharali B, Chandra K (1994). Effect of low light on dry matter production, harvest index and grain yield of rice (Oryza sativa L.) in wet season. Neo-Botanica 2(1):11-14.

Chandrasekaran B, Annadurani K, Kavimant R (2007). A textbook of rice science, Tamil Nadu Agricultural University Coimbatore, P- 4647-667. ISBN: 81-7233-466-4.

Choi HC, Kwon KW (1985). Evaluation of varietal difference and environment variation for some characters related to source and sink in the rice plants. Korean J. Crop Sci. 30:460-470.

Efisue AA, Tongoona P, Derera J, Ubi BE (2009). Screening earlygeneration progenies of interspecific rice genotypes for droughtstress tolerance during vegetative phase. J. Crop Improv. 23:174193. http://dx.doi.org/10.1080/15427520802669036

Feil B. (1992) .Breeding progress in small grain cereals: A comparison of old and modern cultivars. Plant Breed. 108:1-11.

http://dx.doi.org/10.1111/j.1439-0523.1992.tb00093.x

Ghosh DC, Singh BP (1998). Crop growth modeling for weyland rice management. Environ. Ecol. 16(2):446-449.

Halil S, Necmi B (2005). Response two-way selection for harvest index in two wheat (Triticum eastivum L.) crosses. Aust. J. Agric. Res. 28:29-365.

Huang J, David CC, Duff B (1991). Rice in asia: Is it becoming an interior good? Comment. Am. Agric. Econ. 73:513-521.

Ibrahim SM, Ramalingam A, Subramaniam M (1990). Path analysis of rice grain yield under rainfed lowland conditions. IRRN 15(1):11.

International Rice Research Institute (IRRI) (2001). Rice Statistics. Accessed Online http://oryza.com/africa/nigeria/index.shtml on 27th July, 2007.

International Rice Research Institute (IRRI) (1996). Standard evaluation system for rice. Los Baanos, Philippines: IRRI.

Jaccard P (1908). Nouvelles recherches sur la distribution florale. But. Soc. Vaudoise Sci. Natur. 44:223-270

Jeng TL, Wang CS, Chen CL, Sung JM (2003). Effects of grain position on the panicle on starch biosynthetic enzyme activity in developing grains of rice cultivar Tainung 67 and its NaN3-induced mutant. J. Agric. Sci. 141:303-311. http://dx.doi.org/10.1017/S0021859603003599

Jones DB, Peterson ML, Geng S (1979.) Association between grain filling rate and duration and yield components in rice. Crop Sci. 19:641-644.

http://dx.doi.org/10.2135/cropsci1979.0011183X001900050023x

Kole PC, Habib KM (2008). Correlation and regression analysis in scented rice. Madras Agric. J. GS (1-6):178-182.

Mirza JM, Ahmad F, Abdul M. (1992). Correlation Study and Path Analysis of Plant Height, Yield and Yield Component. Sarhad J. Agric. 8(6):647-651.

Mohashami R (1998). A study of genotypic and phenotypical correlation between qualitative and quantitative and quantitative traits and grain yield in rice (Oryza sativa L) using analysis ms Thesis. Sari Agriculture College, Mazandaran University, p. 217.

Ntanos DA, Koutroubas SD (2002). Dry matter and N accumulation and translocation for Indica and Japonica rice under Mediterranean conditions. Field Crops Res. 74:93-101.

http://dx.doi.org/10.1016/S0378-4290(01)00203-9

Peng S, Khush GS, Cassman KG (1994). Evolution of the new plant ideotype for increased yield potential, In: K.G. Cassman (Ed.), Breaking the Yield Barrier. IRRI, Los Banos, Philippines, pp. 5-20.

Prasad B, Patwari AK, Biswas PS (2001). Genetic Variability and selection criteria in fine grain rice (Oryza sativa). Pak. J. Biol. Sci. 4(10):1188-1190.

http://dx.doi.org/10.3923/pjbs.2001.1188.1190

Rohlf FJ (2000). NTSys pc, Version 2.02j. Exeter software, Setauket, New York.

Sneath PHA, Sokal RR (1973). The principle and practice of numerical classification. In: Numerical Taxonomy, Kennedy D and RB Park (Eds.) Freeman, San Francisco.

Swaminathan MS (1999). Rice in 2000 AD. In Abrol and Sulochana Gadgil (Eds.), Rice in a variable climate (pp. 217-238). APC Publications Pvt. Ltd., Post Box No. 2679, New Delhi-110005, India.
Swofford DL, Olsen GJ (1990). Phylogenetic reconstruction in molecular systematics. Hills, D.M. and C. Moritz (Eds.), Sinauer Associates, Sunderland, pp. 411-501.

Xiong ZM (1992). Research outline on rice genetics in China. In 'Rice in China'. (Eds ZM Xiong, HF Cai) pp. 40-57. Chinese Agricultural Science Press: Beijing.

Yan L, Echenique V, Busso C, SanMiguel P, Ramakrishna W (2002). Cross population derived from cultivated Asian (O. sativa L.) Cereal genes similar to Snf2 define a new subfamily African (O. glaberrima S.) rice. Genome 47:697-704.

Yoshida S (1983). Rice. In 'Potential productivity of field crops under different environments'. (Eds WH Smith, SJ Banta) pp. 103-127. (International Rice Research Institute Publishing: Los Bãnos). The Philippines.

Yoshida S (1981). Fundamentals of rice crop science. The International Rice Research Institute (IRRI). Los Banos, Laguna, Philippines, pp. 269. 